\title{
UNA PRIMERA APROXIMACIÓN AL ANÁLISIS DIACRÓNICO DE LA ATENUACIÓN Y LA IMAGEN EN DIÁLOGOS MADRE-HIJO EN EL TEATRO ESPAÑOL EN LOS SIGLOS XIX Y XX
}

\author{
AN APPROXIMATION TO THE DIACHRONIC ANALYSIS OF MITIGATION AND \\ FACE IN DIALOGUES BETWEEN MOTHER AND CHILD IN THE NINETEENTH AND \\ TWENTIETH CENTURIES
}

\author{
Marta Gancedo Ruiz \\ Universitat de València \\ margan123@msn.com
}

Recibido: 21/12/2016

Aceptado: 25/05/2017

\section{Resumen}

Este artículo aborda la evolución del uso de la atenuación en los diálogos madre-hijo y sus efectos en la imagen sociocultural en los siglos XIX y XX. Para ello, utilizando como corpus cuatro obras de teatro de este periodo, se analiza cualitativa y cuantitativamente el empleo de la atenuación como estrategia pragmática en los actos directivos realizados en la proyección de estas relaciones. Los resultados de este estudio apuntan a que se ha producido una evolución desde la jerarquía hacia una progresiva solidaridad.

PALABRAS CLAVE: atenuación, imagen social, actos directivos, pragmática diacrónica, teatro.

\begin{abstract}
This paper aims to analyse the evolution of the use of mitigation in dialogues between mother and child and their effects on sociocultural face in the nineteenth and twentieth centuries. In order to do this, by using a corpus of four plays, a qualitative and quantitative analysis of the use of mitigation as a pragmatic strategy in directive speech acts between mother and children will be developed from a diacronic perspective. The result suggests that an evolution has been produced from the hierarchy to a progressive solidarity.

KEY WORDS: mitigation, social face, directive speech acts, diachronic pragmatics, theatre plays.
\end{abstract}

Para citar este artículo / To cite this article: Gancedo Ruiz, Marta (2018): Una primera aproximación al análisis diacrónico de la atenuación y la imagen en diálogos madre-hijo en el teatro español en los sigos XIX y XX. García Ramón, Amparo y Soler Bonafont, María Amparo (Eds.): ELUA: Estudios de atenuación en el discurso, Anexo IV, págs. 157-178.

Enlace / Link: http://dx.doi.org/10.14198/ELUA2018.Anexo4.09 


\section{INTRODUCCIÓN}

Son muchos los estudios pragmáticos que se han centrado en el análisis de las diferencias situacionales y culturales en el uso de las estrategias pragmáticas (Wierzbika 1985; Cestero 2015; Bravo 1998, 1999, 2010; Briz 2003, 2005, 2006, 2012; Schrader-Kniffki 2003; Albelda 2004, 2008; Albelda y Contreras 2009, entre muchos otros). Sin embargo, apenas los hay desde una perspectiva histórica. Si se observan textos de siglos o, incluso, de décadas anteriores, puede apreciarse que el modo de establecer relaciones en los diferentes contextos socioculturales ha cambiado $\mathrm{y}$, con ello, también han evolucionado las estrategias pragmáticas y sus funciones y manifestaciones lingüísticas.

Este aspecto ha suscitado el interés de los investigadores hacia la dimensión diacrónica de la pragmática, así como la "extensión de la lingüística histórica hacia aspectos pragmáticos" (Faya Cerqueiro y Vila Carneiro 2014: 55). No obstante, dado el reciente desarrollo de la pragmática histórica, no son profusos los estudios que abordan el análisis de estrategias pragmáticas desde una perspectiva diacrónica y, menos aún, aquellos realizados sobre el español.

En este artículo adoptamos la perspectiva diacrónica para realizar un primer acercamiento al estudio histórico de una estrategia pragmática específica, la atenuación, y sus efectos en la imagen de los interlocutores en los roles de madres e hijos. Específicamente, nuestro arco temporal estudiado abarca desde comienzos del siglo XIX a la década de los 80 del siglo XX. Para esta primera aproximación, se analiza en este artículo la atenuación en cuatro obras de teatro (cuyo número será ampliado en futuros trabajos) de diferentes periodos dentro de la horquilla temporal mencionada: El sí de las niñas (1806), La bola de nieve (1856), Historia de una escalera (1949) y Fuiste a ver a la abuela??? (1979). Metodológicamente, partimos del análisis de la presencia o ausencia de esta estrategia en los actos de habla directivos identificados en los intercambios entre los personajes en los roles de madres e hijos y estudiamos los efectos de imagen producidos. Así, en una próxima fase de la investigación se pretende, además de incorporar variables sociolingüísticas, averiguar si los resultados arrojados por el análisis pragmático en las obras examinadas se corresponden o no con los patrones de conducta familiar imperantes de cada época.

Para esta primera caracterización de la atenuación como estrategia pragmática en los diálogos entre madres e hijos, partimos en este trabajo de una doble hipótesis; por un lado, manejamos el supuesto de que desde el siglo XIX hasta finales del siglo XX se ha producido un cambio en las relaciones materno-filiales, de modo que estas se han desplazado desde un tratamiento jerárquico hacia una progresiva solidaridad (Brown y Gilman 1960: 260-261). Por otro lado, presuponemos que pese al alto grado de convención estilística que pueda tener la lengua literaria, a través de las estrategias lingüísticas (concretamente, del uso de la atenuación) elegidas por el autor para caracterizar los diálogos de sus personajes, puede estudiarse la evolución de aspectos socioculturales, en este caso, de las relaciones entre madres e hijos.

De este modo, este artículo comienza con la delimitación de la disciplina en la que se inscribe y con un breve repaso al estado de la cuestión de los estudios diacrónicos de aspectos pragmáticos en textos literarios en el ámbito hispánico (§ 2). En segundo lugar, se esboza un breve marco teórico en el que se presentan los conceptos básicos sobre los que se sustenta esta investigación (imagen sociocultural, imagen de rol, atenuación) (§ 3). A continuación, después de describir el corpus y la metodología (§ 4.1) adoptada, se desarrolla el análisis de 
los actos directivos en intercambios entre madres e hijos en cuatro obras de teatro de diferentes periodos (§ 4.2), a la luz de cuyos resultados presentamos las conclusiones extraídas $(\S 5)$.

\section{PRAGMÁTICA HISTÓRICA Y TEXTOS LITERARIOS}

Fue en el año 1985 cuando Stein, en su obra Perspectives on historical pragmatics, acuñó por primera vez el término pragmática histórica, disciplina en la que ubicaba aspectos como el estudio histórico de los actos de habla, la relación entre cambios lingüísticos y cambios sociales, así como algunos trabajos relacionados con la pragmática literaria (Faya Cerqueiro y Vila Carneiro 2014: 56). Sin embargo, no fue hasta mediados de la década de los noventa cuando esta área de estudio comenzó a desarrollar cierto impulso (siempre a la sombra del auge de los estudios de pragmática contemporánea) con la publicación de Historical Pragmatics (Jucker 1995), obra en la que se propone un marco teórico para este ámbito de conocimiento.

Definida por Taavitsainen y Fitzmaurice (2007) como una disciplina cuyo objeto de estudio se centra en "language use in past contexts and examines how meaning is made. It is an empirical branch of linguistic study, with focus on authentic language use in past" (2007: 13), la pragmática histórica se subdivide a su vez, según Jacobs y Jucker (1995), en dos subdisciplinas. Por un lado, se encuentra la pragmafilología, encargada de estudiar "los aspectos contextuales de los textos históricos, incluyendo sus emisores y sus destinatarios, las relaciones sociales y personales de estos, la situación social de la producción y recepción de los textos, así como los propósitos de estos" (Padilla Cruz, 2002: 472). Por otro lado, se desarrolla la pragmática diacrónica, cuya atención se centra en "el inventario lingüístico y sus usos comunicativos a lo largo de las etapas históricas de una misma lengua" (Ibídem). Es en esta última en la que se ubica este artículo, ya que en él partimos de una estrategia comunicativa en concreto (la atenuación), y analizamos sus situaciones de aparición y efectos sociales, así como las formas en las que se ha manifestado en diferentes periodos.

Desde sus comienzos, la pragmática diacrónica se topó con el gran escollo de encontrar corpus adecuados para sus análisis, ya que, por cuestiones obvias, solo puede acceder a los textos escritos. Ante esta dificultad, los autores han acudido a diferentes tipologías textuales, como, entre otras muchas, cartas personales (Bentivoglio 2003), textos administrativos entre la metrópoli y colonias y textos judiciales (Carrera de la Red 2012, 2013, 2015; Carrera de la Red y Álvarez 2004) o textos médicos (Taavitsainen 2002). No obstante, hemos seguido el ejemplo de autores como Goffman (1959), Brown y Gilman (1989), Culpeper (1996), Padilla Cruz (1998a, 1998b) o Iglesias Recuero (2010, 2016), quienes realizan sus estudios pragmáticos sobre textos literarios.

Dentro de las diferentes tipologías de textos literarios, pese a la existencia de interesantes estudios pragmáticos en el ámbito hispánico realizados sobre novelas (Haverkate 2001; García Aguiar 2012; Zamora 2014; Iglesias Recuero 2016) o lírica (Schrott 2000; Hamad Zahonero 2012), nos decantamos por el análisis de obras teatrales ya que, como explicamos en Gancedo Ruiz (2016), este género posee diversas ventajas frente a los demás. Este tipo de estudios sobre el español son muy poco numerosos, pero merecen mención los trabajos históricos sobre la cortesía de Haverkate (1991), quien analiza diálogos de La Celestina y de Moreno (2002, 2008), quien estudia la cortesía en el teatro del Siglo de Oro. Igualmente son reseñables de esta época los análisis de las fórmulas de tratamiento que realiza Navarro Gala (2004) de La 
Segunda Celestina e Iglesias Recuero (2010), quien en la misma obra y en Comedia llamada Selvagia realiza un análisis acompañado de una profunda reflexión metodológica sobre el estudio histórico de la cortesía. Por su parte, Pedroviejo Esteruelas (2004), desarrolla un análisis de los sistemas de tratamiento en Historia de una escalera y Bajarse al moro. Del mismo modo, resultan de gran interés los análisis de los marcadores pragmáticos hola y adiós que realizan Faya Cerqueira y Vila Carneiro $(2014,2016)$ en el teatro de Calderón.

No obstante, no se conoce -al menos hasta donde hemos podido averiguar- ningún trabajo que se centre en la evolución de una determinada estrategia pragmática (como hacemos en este caso con la atenuación), y tampoco con el análisis de aspectos de imagen en determinados roles. Es, pues, en el análisis de una estrategia pragmática concreta en un tipo determinado de relación socio-funcional en donde reside nuestra principal aportación, cuyos principales aspectos teóricos definimos en el siguiente epígrafe.

\section{LA ATENUACIÓN EN LAS ACTIVIDADES DE IMAGEN DE ROL}

Los contextos socioculturales evolucionan, y con ello irremediablemente cambia la manera de entablar las relaciones personales. Así, dado que la lengua es la principal herramienta de socialización con la que el ser humano cuenta, esta refleja los cambios sociales, ya que, como sujeto social, el hablante debe adecuar sus intervenciones a la imagen que de sí mismo desea transmitir.

En este trabajo nos apoyamos en la noción de imagen (face) sugerida por Bravo (1998, 1999, 2002, 2004, 2010, entre otros), la cual incluye la revisión de trabajos anteriores (Goffman 1959; Wierzbicka 1985, 1991; Brown y Levinson 1987; Matsumoto 1988; Arundale 2006, 2013; entre muchos otros) y que ha dado comienzo a toda una corriente teórica denominada pragmática sociocultural (Bravo 2010).

De acuerdo con Bravo, la imagen del hablante se define como la representación de sí mismo que el individuo desea transmitir en sus relaciones con los demás y que está sujeta a variedades socioculturales. Se trata, por tanto, de un concepto no universal sino determinado por la comunidad sociocultural del hablante. Así, la imagen del individuo se compone de dos categorías universales: por una parte, las necesidades de autonomía (todo lo que hace a la persona diferenciarse del grupo) y por la otra, las necesidades de afiliación (todo lo que permite a la persona identificarse con el grupo). Sostiene Bravo $(1999,2002)$ que estas categorías están vacías en tanto que cada comunidad las completa con unos contenidos socioculturales propios, determinados por el contexto sociocultural.

En lo que se refiere a la imagen sociocultural española, se ha establecido en diferentes estudios (Bravo 1999; Hernández Flores 2002, 2003) que la autodeterminación, "el deseo de mostrarse original y consciente de las buenas cualidades propias" (Bravo 1999: 168-169) sería un contenido sociocultural propio asociado a las necesidades de autonomía españolas, y la confianza, "saber a qué atenerse con respecto al otro y que se puede hablar sin temor a ofensas" (Ibídem), configuraría parte de las necesidades de afiliación. La imagen social que cada hablante defiende en sus intervenciones no es continua, sino que es temporal, interaccional y está "circunstancialmente acotada" (Bravo 2002: 101). Uno de los aspectos que determina la imagen que cada hablante defiende es el rol que ostenta en cada situación de habla, es decir, la "posición adoptada por el individuo en una situación concreta" (Hernández Flores 2003: 123). Este concepto está fuertemente vinculado con la imagen social 
en tanto que "en una situación de habla el deseo de imagen de una persona depende del rol que representa en cada situación de habla concreta" (Ibídem: 124).

Por lo tanto, un análisis como el que en este artículo desarrollamos de cómo se gestiona la conversación entre hablantes que desempeñan roles determinados (en este caso, de madre e hijo) en situaciones de habla de diferentes periodos, puede dar información al investigador sobre la concepción de la imagen propia de cada rol en diferentes etapas de la historia, pues "en conversación, la imagen social se manifiesta en la actuación del «ego» frente al «alter» y en esta medida está unida a cómo se concibe una relación interpersonal en una situación determinada" (Bravo 2002: 15).

Para gestionar su propia imagen de rol, y puesto que esta es susceptible de ser dañada, ensalzada o mantenida en cualquier momento de la interacción (Hernández Flores 2004), el hablante emplea una serie de estrategias (verbales o no verbales) conocidas como actividades de imagen (facework: Goffman 1959; Bravo 1999, 2002, 2003; Watts y Locher, 2005; Hernández Flores 2013, entre otros). Siguiendo a Hernández Flores (2013), estas actividades de imagen, en función del efecto que consigan en el interlocutor, pueden clasificarse en tres subtipos: actividades de cortesía (aquellas que buscan el equilibrio entre las imágenes de los interlocutores), actividades de autoimagen (aquellas que buscan el beneficio de la imagen del hablante y tienen un efecto neutro sobre el oyente) y actividades de descortesía (aquellas que generan un daño en la imagen de alguno de los involucrados en el intercambio comunicativo). De este modo, sugiere la autora que las actividades de imagen siempre tienen un efecto social bidireccional (en emisor y en oyente), puesto que las imágenes de los interlocutores quedan conectadas en el momento de la interacción.

Para realizar una actividad de imagen, el hablante puede utilizar diferentes estrategias pragmáticas, una de las cuales -y entre las más frecuentes- es la atenuación, en cuyo estudio nos centramos en este artículo.

Esta estrategia comunicativa ha sido foco de numerosos estudios en los últimos años (Fraser 1980; Holmes 1984; Briz 1998, 2003, 2006, 2012; Caffi 1999, 2007; Sbisà 2001; Albelda, 2008, 2010, 2016; Thaler 2012; Schneider 2013; Albelda et alii 2014; entre otros), entre los cuales, la línea de investigación que más nos concierne para nuestro análisis es aquella dirigida a discernir la relación intrínseca o no entre atenuación e imagen (Briz 2005, 2006; Albelda 2016). Partimos aquí de la concepción de que la atenuación se desencadena por necesidades de imagen:

la atenuación es una estrategia pragmática (comunicativa) originada por necesidades de imagen y dirigida a mitigar y minimizar la intensidad de lo que se expresa reduciendo la fuerza ilocutiva del acto de habla, y en ocasiones, a través de mecanismos de lenguaje vago por los que se difumina o minimiza el contenido proposicional. La atenuación es, al mismo tiempo, una actividad argumentativa que permite a los hablantes formular un menor compromiso hacia lo dicho y así lograr más eficazmente las metas conversacionales de los participantes en el discurso (Albelda 2016: 30).

De este modo, a partir de esta continuidad entre atenuación e imagen, pretendemos realizar un análisis histórico de esta estrategia pragmalingüística, para comprobar si a través de ello es posible caracterizar la evolución de un fenómeno sociopragmático, las imágenes de los roles de madre e hijo en los siglos XIX y XX, en su reflejo en las cuatro obras de teatro seleccionadas. 


\section{ANÁLISIS DIACRÓNICO DE LA ATENUACIÓN EN LOS DIÁLOGOS MA- DRE-HIJO EN LOS SIGLOS XIX Y XX}

\subsection{Descripción del corpus y metodología}

Como se ha mencionado en $\S 2$, uno de los principales problemas de la pragmática diacrónica es la obtención de un corpus de lengua real, escollo que en este trabajo hemos solventado recurriendo a los textos teatrales. Con base en el objetivo de análisis planteado, realizar una aproximación a la caracterización de la evolución de las relaciones maternofiliales a través del estudio de la atenuación como estrategia pragmática en obras de teatro de los siglos XIX y XX, han sido elegidas, como punto de partida de una investigación que será completada en el futuro, cuatro obras de teatro: El sí de las niñas (Fernández de Moratín 1806) representativa de la primera mitad del siglo XIX, La bola de nieve (Tamayo y Baus 1856) ilustrativa de la lengua de la segunda mitad decimonónica, Historia de una escalera (Buero Vallejo 1949) para cubrir el arco temporal de la primera mitad del siglo XX y Fuiste a ver a la abuela??? (Cabal 1979) perteneciente al periodo postfranquista. Estas cuatro obras representan periodos significativamente diferentes en las relaciones maternofiliales en situaciones cotidianas (una posada, una escalera de vecinos, la casa familiar) y desarrollan como parte central de la obra relaciones de esta índole; además, su lengua ha sido considerada tradicionalmente realista, y por lo tanto, representativa de la lengua propia de su momento social.

Para la realización de este análisis, sobre la lectura global del texto hemos acotado las muestras de lengua analizadas a los actos directivos realizados entre madres e hijos ya que, por su propia naturaleza, este tipo de actos de habla, al apelar al interlocutor (Albelda y Contreras 2009; Albelda 2010), afectan irremisiblemente a la imagen de los dos hablantes (Hernández Flores 2002, 2004, 2006, 2013). Así, al suponer siempre una amenaza para la imagen, la presencia o no de atenuación es un dato representativo para interpretar la distancia social que el hablante considera que mantiene con su interlocutor, de modo que de ello se desprenderá el grado de jerarquía concebida en la relación, en este caso, materno-filial concreta, en el periodo determinado.

Estos actos de habla directivos, siguiendo a Albelda et alii (2014), han sido subdivididos en dos grupos: por una parte, en actos directivos a favor del hablante, los cuales además de reflejar el grado de autoridad que concibe el hablante que tiene sobre el receptor, suponen una gran amenaza para ambos interlocutores, especialmente para las necesidades de autonomía del receptor; por la otra parte, en actos de habla directivos a favor del oyente, en los que la amenaza a las necesidades de autonomía del receptor, aunque sigue muy presente, es menor. A su vez, hemos establecido una ulterior diferenciación en el análisis: los actos de habla directivos a favor del hablante han sido subclasificados en orden de menor a mayor grado de amenaza a las imágenes en preguntas de información, solicitudes y órdenes; por su parte, los actos directivos a favor del oyente han sido divididos, siguiendo el mismo orden y criterio que los anteriores, en consejos o sugerencias y advertencias.

Para el análisis cuantitativo hemos contabilizado todos los actos directivos realizados, por una parte, por las madres hacia sus hijos, y por otra, por los hijos a sus madres. De este total de directivos hemos extraído los porcentajes pertenecientes a cada subtipo de 
directivo. Tras esto, hemos analizado la presencia o no de atenuación en cada uno de los grupos establecidos y calculado los porcentajes del total de actos atenuados tanto sobre el total de cada uno de los grupos como del total de actos directivos. Después del análisis cuantitativo, desarrollamos un breve análisis cualitativo (solo de los casos más significativos de cada obra por cuestiones de espacio) en el que se explican los efectos sociales en la relación socio-funcional materno-filial y damos una posible interpretación de los datos obtenidos.

\subsection{Análisis}

\subsubsection{El sí de las niñas (Fernández de Moratín 1806)}

El sí de las niñas ha pasado a la historia de la literatura española no solo por el éxito que cosechó en la época, sino por canalizar una crítica hacia la actitud sumisa a la voluntad materna que imperaba a finales del siglo XVIII y principios del XIX. Dicha sumisión responde por tanto a una relación jerárquica que prevalecía entre madres e hijas en la que las madres (en esta obra representadas por doña Irene), desempeñaban el rol de poder con respecto a sus hijas (reflejadas en el personaje de doña Francisca). A continuación, se reproducen los datos obtenidos de la obra (vid. Tablas 1 y 2):

\begin{tabular}{|c|c|c|c|}
\hline Directivos a favor del hablante & & Directivos a favor del oyente & \\
\hline $\begin{array}{r}\text { atenuadas (1) } \\
\text { no atenuadas (3) }\end{array}$ & $\begin{array}{l}40 \% \\
25 \% \\
75 \%\end{array}$ & $\begin{array}{r}\text { Consejos o sugerencias }(0) \\
\text { atenuadas }(0) \\
\text { no atenuadas }(0)\end{array}$ & $\begin{array}{l}0 \% \\
0 \% \\
0 \%\end{array}$ \\
\hline $\begin{array}{r}\text { atenuadas (0) } \\
\text { no atenuadas (0) }\end{array}$ & $\begin{array}{ll}0 \% \\
0 \% \\
0 \%\end{array}$ & $\begin{array}{r}\text { Advertencias en beneficio del } \\
\text { oyente (2) } \\
\text { atenuadas (1) } \\
\text { no atenuadas (1) }\end{array}$ & $\begin{array}{l}100 \\
\% \\
50 \% \\
50 \%\end{array}$ \\
\hline $\begin{array}{r}\text { atenuadas (2) } \\
\text { no atenuadas (6) }\end{array}$ & $\begin{array}{l}60 \% \\
25 \% \\
75 \%\end{array}$ & & \\
\hline $\begin{array}{l}\text { Total directivos a favor del hablante: } 12 \\
\text { Atenuados: } 25 \%(3) \\
\text { No atenuados: } 75 \%(9)\end{array}$ & & $\begin{array}{l}\text { Directivos a favor del oyente: } 2 \\
\text { Atenuados: } 50 \%(2) \\
\text { No atenuados: } 50 \%(2)\end{array}$ & \\
\hline $\begin{array}{l}\text { TOTAL actos de habla directivos: } 14 \\
\text { Actos de habla directivos atenuados: } 28,5 \% \text { (4) } \\
\text { Actos de habla directivos no atenuados: } 71,4 \% \\
\text { (10) }\end{array}$ & & & \\
\hline
\end{tabular}

Tabla 1. Datos de los actos directivos realizados por el personaje en rol de madre en El sí de las niñas (1986). 


\begin{tabular}{|c|c|c|c|}
\hline Directivos a favor del hablante & & Directivos a favor del oyente & \\
\hline $\begin{array}{r}\text { Preguntas de información (2) } \\
\text { atenuadas (2) } \\
\text { no atenuadas }(0)\end{array}$ & $\begin{array}{l}28,5 \% \\
100 \% \\
0 \%\end{array}$ & $\begin{array}{r}\text { Consejos o sugerencias }(0) \\
\text { atenuadas }(0) \\
\text { no atenuadas }(0)\end{array}$ & $\begin{array}{l}0 \% \\
0 \% \\
0 \%\end{array}$ \\
\hline $\begin{array}{r}\text { atenuadas }(5) \\
\text { no atenuadas }(0)\end{array}$ & $\begin{array}{l}71,5 \% \\
100 \% \\
0 \%\end{array}$ & $\begin{array}{r}\text { Advertencias en beneficio del oyente (1) } \\
\text { atenuadas }(1) \\
\text { no atenuadas }(0)\end{array}$ & $\begin{array}{l}100 \% \\
100 \% \\
0 \%\end{array}$ \\
\hline $\begin{array}{r}\text { atenuadas }(0) \\
\text { no atenuadas }(0)\end{array}$ & \begin{tabular}{ll|}
0 & $\%$ \\
0 & $\%$ \\
0 & $\%$ \\
\end{tabular} & & \\
\hline $\begin{array}{l}\text { Total directivos a favor del hablante: } 7 \\
\text { Atenuados: } 100 \%(7) \\
\text { No atenuados: } 0 \%(0)\end{array}$ & & $\begin{array}{l}\text { Directivos a favor del oyente: } 1 \\
\text { Atenuados: } 100 \%(1) \\
\text { No atenuados: } 0 \%(0)\end{array}$ & \\
\hline \multicolumn{4}{|c|}{$\begin{array}{l}\text { TOTAL actos de habla directivos: } 7 \\
\text { Actos de habla directivos atenuados: } 100 \%(7) \\
\text { Actos de habla directivos no atenuados: } 0 \%(0)\end{array}$} \\
\hline
\end{tabular}

Tabla 2. Datos de los actos directivos realizados por el personaje en rol de hija en El si de las niñas (1986).

En primer lugar, el número de actos directivos que realiza doña Irene (14) es justamente el doble de los que realiza su hija (7), doña Francisca. Este hecho puede ser un primer indicador de que la obra plasma una relación materno-filial con una gran distancia sociofuncional entre madre e hija. Esto puede predisponer ya a una mayor frecuencia en los comportamientos comunicativos directivos de la madre a la hija, ya que, en esta relación de poder, la necesidad de autonomía de las hijas queda supeditada a la voluntad materna.

Se observa, además, que en el total de actos directivos a favor del hablante realizados por la madre, esta solo atenúa en cuatro ocasiones. Así, en los siguientes ejemplos, puede observarse cómo la atenuación canaliza actividades de cortesía que tratan de restablecer el equilibrio de las imágenes de ambas ya que han surgido previamente dos conflictos (la posibilidad de que doña Francisca quiera convertirse en monja y el conocimiento de doña Irene del idilio entre su hija y el sobrino de su prometido) en los que la reacción de doña Irene se plantea desmesurada. De este modo, en dos ocasiones utiliza la táctica lingüística del apelativo con diminutivo para mitigar la fuerza ilocutiva de su advertencia (1) y de su orden (2) y reforzar la afiliación con su hija:

(1) Doña Irene: Todos los estados se sirve a Dios, Frasquita, pero el complacer a su madre, asistirla, acompañarla y ser el consuelo de sus trabajos, ésa es la primera obligación de una hija obediente.

(2) Doña Irene: Ven aquí, ven... Ven aquí, Paquita. (p. 130)

En la tercera de las ocasiones, además del apelativo cariñoso a su hija, que atenúa la amenaza a la imagen previa de la joven (doña Irene ha reaccionado violentamente con ella), la táctica lingüística es la expresión indirecta de una petición expresada a través de una forma lingüística interrogativa: 
(3) Doña Irene: ¡Hija de mi vida! ¿Has de ser buena? (p. 131)

Sin embargo, en el resto de las intervenciones directivas en las que no ha habido un conflicto previo que desequilibre las imágenes de las interlocutoras (el 71,4\% de los actos directivos), no se observa ningún mecanismo de atenuación en las emisiones de doña Irene, como se aprecia en los siguientes ejemplos:

(4) Doña Irene: Anda, vete. ¡Válgate Dios, qué prisa tienes! (p. 88)

(5) Doña Irene: ¿Pues no ha de estarlo? Responde. (p. 91)

Radicalmente diferente es el comportamiento comunicativo de doña Francisca, en el rol de hija. Si ya puede ser significativo el hecho de que solo realice 7 actos directivos en toda la obra, más lo es el hecho de que atenúe en el $100 \%$ de los casos.

Si bien no realiza ninguna orden, la hija emite 5 solicitudes, las cuales atenúa con una actividad de cortesía, ya que al tomar una iniciativa, atenta contra las necesidades de afiliación al rol de hija sumisa, lo que a su vez supone una amenaza para la imagen de rol de madre de doña Irene. Esta actividad de cortesía la realiza a través de la estrategia pragmática de atenuación, que a su vez se concreta a través de diferentes tácticas lingüísticas: indirección de la petición en forma de interrogación (7) y (8), fórmula apelativa convencionalizada mamá (7), (8) y (10) y el movimiento concesivo que minimiza la petición posterior (9).

(6) Doña Francisca: ¿Nos vamos adentro, mamá, o nos quedamos aquí? (p. 83)

(7) Doña Francisca: ¿Me voy, mamá? (p. 85 y 87)

(8) Doña Francisca: Bien, sí señora, ya lo sé. No me riña usted más. (p. 114)

(9) Doña Francisca: Mamá, no se enfade usted. (p. 119)

Del mismo modo, para cumplir con su rol de hija sumisa y discreta, doña Francisca utiliza la atenuación como estrategia de cortesía en las dos ocasiones en las que realiza una pregunta de información. En el caso de (10), la joven modaliza el tiempo verbal utilizando el pretérito imperfecto por el presente, mientras que en (11) justifica su necesidad de preguntar mediante la expresión de adversidad:

(10) Doña Francisca: ¿Me llamaba usted? (p. 208)

(11) Doña Francisca: Pero, ¿qué sabe usted? (p. 120)

Por lo tanto, puede observarse que los usos de atenuación de la madre están encaminados en su mayoría al refuerzo de sus necesidades de afiliación a un rol de madre autoritaria. Por su parte, los efectos de la atenuación sobre la imagen de doña Francisca afectan principalmente a sus necesidades igualmente de afiliación, pues de este análisis se puede inferir que no era frecuente la preocupación por las necesidades de autonomía de las hijas. Se trata, por tanto, de una relación jerárquica vertical basada en la autoridad en la que la madre ostenta un destacado rol de poder. 


\subsubsection{La bola de nieve (Tamayo y Baus, 1856)}

Entre las corrientes románticas y exaltadas de finales del siglo XIX, se desarrolla un teatro realista de corte costumbrista. Entre los representantes de este movimiento hemos elegido a Manuel Tamayo y Baus y su obra La bola de nieve, que refleja una serie de conflictos familiares surgidos por los celos de Clara y Luis, hijos de la Marquesa, entre cuyos diálogos se han registrado los siguientes datos en la realización de los actos directivos (vid. Tablas 3 y 4 ).

\begin{tabular}{|c|c|c|c|}
\hline Directivos a favor del hablante & & Directivos a favor de oyente & \\
\hline $\begin{array}{r}\text { Preguntas de información (11) } \\
\text { atenuadas (3) } \\
\text { no atenuadas (8) }\end{array}$ & $\begin{array}{l}55 \% \\
2 \\
7,7 \% \\
72,72 \%\end{array}$ & $\begin{array}{r}\text { Consejos o sugerencias }(0) \\
\text { atenuadas }(0) \\
\text { no atenuadas }(0)\end{array}$ & $\begin{array}{ll}0 \% \\
0 \% \\
0 \%\end{array}$ \\
\hline $\begin{array}{r}\text { atenuadas }(0) \\
\text { no atenuadas }(0)\end{array}$ & $\begin{array}{ll}0 & \% \\
0 & \% \\
0 & \%\end{array}$ & $\begin{array}{l}\text { Advertencias en beneficio del oyente } \\
\begin{aligned} &(0) \text { atenuadas }(0) \\
& \text { no atenuadas }(0)\end{aligned}\end{array}$ & $\begin{array}{l}0 \% \\
0 \% \\
0 \%\end{array}$ \\
\hline $\begin{array}{r}\text { Atenuadas (5) } \\
\text { no atenuadas (4) }\end{array}$ & $\begin{array}{l}45 \% \\
55,55 \% \\
44,44 \%\end{array}$ & & \\
\hline \multicolumn{2}{|l|}{$\begin{array}{l}\text { Total directivos a favor del hablante: } 20 \\
\text { Atenuados: } 40 \%(8) \\
\text { No atenuados: } 60 \%(12)\end{array}$} & \multicolumn{2}{|l|}{$\begin{array}{l}\text { Directivos a favor del oyente: } 0 \\
\text { Atenuados: } 0 \% \\
\text { No atenuados: } 0 \%\end{array}$} \\
\hline \multicolumn{4}{|c|}{$\begin{array}{l}\text { TOTAL: } 20 \\
\text { Actos de habla directivos atenuados: } 40 \%(8) \\
\text { Actos de habla directivos no atenuados: } 60 \%(12)\end{array}$} \\
\hline
\end{tabular}

Tabla 3. Datos de los actos directivos realizados por el personaje en rol de madre en La bola de nieve (1856).

Como se desprende de las tablas (vid. Tablas 3 y 4), si bien la cantidad de actos directivos realizados por el personaje de la madre y por los personajes de los hijos es similar al desarrollado en El si de las niñas, hay una gran diferencia en las motivaciones y efectos sociales de los mismos. Por un lado, observamos que aunque sigue habiendo mayoría de actos no atenuados, el número de actos de habla directivos atenuados ha aumentado (del $28,5 \%$ de la obra de comienzos de siglo al $40 \%$ de la obra de Tamayo y Baus). Esto puede deberse, lo que será confirmado o refutado en el estudio socio-histórico que se desarrollará en la siguiente fase de esta investigación, a que pese a que el rol de poder en la segunda mitad del siglo XIX lo siga ostentando la madre, la distancia socio-funcional se vio levemente reducida. Al mismo tiempo, se da una inversión en el comportamiento comunicativo de los hijos en el empleo de la atenuación, ya que en los siete actos directivos realizados por los hijos hacia su madre no atenúan en ninguno, lo que parece reforzar nuestra hipótesis. 


\begin{tabular}{|c|c|c|c|}
\hline Directivos a favor del hablante & & Directivos a favor de oyente & \\
\hline $\begin{array}{r}\text { Preguntas de información (6) } \\
\text { atenuadas (0) } \\
\text { no atenuadas (6) }\end{array}$ & $\begin{array}{l}85,7 \% \\
0 \% \\
100 \%\end{array}$ & $\begin{array}{r}\text { Consejos o sugerencias }(0) \\
\text { atenuadas }(0) \\
\text { no atenuadas }(0)\end{array}$ & $\begin{array}{l}0 \% \\
0 \% \\
0 \%\end{array}$ \\
\hline $\begin{array}{r}\text { atenuadas }(0) \\
\text { no atenuadas }(0)\end{array}$ & $\begin{array}{l}0 \% \\
0 \% \\
0 \%\end{array}$ & $\begin{array}{l}\text { Advertencias en beneficio del } \\
\text { oyente (0) } \\
\qquad \begin{array}{r}\text { atenuadas }(0) \\
\text { no atenuadas }(0)\end{array}\end{array}$ & $\begin{array}{l}0 \% \\
0 \% \\
0 \%\end{array}$ \\
\hline $\begin{array}{r}\text { atenuadas (0) } \\
\text { no atenuadas (1) }\end{array}$ & $\begin{array}{l}14,3 \% \\
0 \% \\
100 \%\end{array}$ & & \\
\hline \multicolumn{2}{|l|}{$\begin{array}{l}\text { Total directivos a favor del hablante: } 7 \\
\text { Atenuados: } 0 \% \\
\text { No atenuados: } 100 \%\end{array}$} & \multicolumn{2}{|l|}{$\begin{array}{l}\text { Directivos a favor del oyente: } 0 \\
\text { Atenuados: } 0 \% \\
\text { No atenuados: } 0 \%\end{array}$} \\
\hline \multicolumn{4}{|c|}{$\begin{array}{l}\text { TOTAL: } 7 \\
\text { Actos de habla directivos atenuados: } 0 \%(0) \\
\text { Actos de habla directivos no atenuados: } 100 \%(7)\end{array}$} \\
\hline
\end{tabular}

Tabla 4. Datos de los actos directivos realizados por los personajes en rol de hijos en La bola de nieve (1856).

En lo que respecta al comportamiento comunicativo de la Marquesa, quien desempeña el rol de madre, se desprende de los datos (vid. Tabla 3) que sigue ostentando un rol determinante de poder, lo que puede interpretarse por la ausencia de cualquier acto de habla directivo en favor del oyente (aquellos con menos fuerza ilocutiva y por tanto, con menor grado de amenaza sobe los interlocutores). Por el contrario, son hegemónicos aquellos directivos en favor del hablante, más amenazadores para la imagen de los interlocutores que los del primer tipo. No obstante, se observa que, de las 9 órdenes que emite, 5 de ellas (el $55,5 \%$ ) son atenuadas, lo que supone un sensible aumento en el empleo de esta estrategia de imagen en este tipo de actos de habla. En cuanto a las tácticas lingüísticas utilizadas, son semejantes a las que aparecen en El sí de las niñas, ya que, como se observa en los ejemplos (12) y (13), la Marquesa utiliza la indirección (a través de la forma interrogativa en (12) y de la forma afirmativa en (13)) para mitigar la fuerza ilocutiva de su mandato al establecer la celebración de las dos bodas no deseadas por sus hijos:

(12) Marquesa: ¿Callarás? (Acto primero)

(13) Marquesa: Dentro de muy pocos dias aqui se celebrarán las dos bodas.

Luis: ¿Qué dos bodas?

Marquesa: Toma, las vuestras.

Este incremento de la atenuación de las órdenes puede estar relacionado con un ligero aumento de la importancia de las necesidades de autonomía de los hijos, sin minimizarse 
asimismo la autoridad que las madres ejercen sobre ellos. Esto puede verse reflejado en la siguiente intervención (14) de la Marquesa en la que, si bien se formula una pregunta de información directa y una orden a través de un imperativo intensificada por el adverbio pronto y el sufijo aumentativo - azos en el adjetivo de carga negativa picaronazos, se observan dos estrategias de atenuación a través de la táctica de los apelativos apreciativos:

(14) Marquesa: Clarita, ¿qué les habéis hecho? Pronto, contestad, picaronazos, ¡Ay hijos de mi alma! (Acto segundo)

De este modo, la Marquesa previene la amenaza a las necesidades de autonomía de su hija, que provocará con su interrogación y la orden, a través de la apelación con el sufijo diminutivo -ita, que refuerza las necesidades de autonomía de la joven (es identificada como individuo a través de su nombre propio). Al mismo tiempo, reduce la distancia social entre ellas a través del diminutivo apreciativo -ita. Del mismo modo, con el apelativo hijos de mi alma, la Marquesa realiza una actividad de cortesía reforzando la afiliación entre ella y sus hijos, que se había visto dañada con el acto directivo intensificado; al mismo tiempo repara el daño sufrido a las necesidades de autonomía de sus hijos por el imperativo.

Se observa, asimismo, un incremento sustancial en el número de preguntas de información que la Marquesa realiza a los hijos, lo que puede ser suscitado igualmente por el aumento de la autonomía de estos: son sujetos independientes que pueden conocer información desconocida por los padres. Estas preguntas solo son atenuadas en el 27,7 \% de los casos, en las que se aprecian como tácticas favoritas de atenuación, nuevamente, la modalización del tiempo verbal (se usa el futuro por presente) (15), el uso de diminutivo (15) y la generalización apelando a la primera persona del plural (16):

(15) Marquesa: ¿Habrá ganillas? (Acto primero)

(16) Marquesa: Sepamos, ¿qué es esto? (Acto segundo)

De nuevo aparece en (16) el refuerzo de la afiliación entre madre e hijos, ausente en la obra El sí de las niñas. En la escena, pese a ser la madre la única con autoridad para resolver el conflicto, trata de equilibrar su imagen con la de sus hijos a través de una actividad de cortesía al atenuar la fuerza ilocutiva de su pregunta mediante el empleo de la primera persona del plural.

En lo que respecta al comportamiento comunicativo de Clara y Luis (vid. Tabla 4), hijos de la Marquesa, cabe resaltar respecto a las diferencias con doña Francisca, personaje en el rol de hija de la obra del periodo anterior, que la emisión de actos de habla de solicitación ha sido sustituida por la realización de preguntas directas en las que no se produce atenuación de ningún tipo. Esto puede deberse al aumento de las necesidades de autonomía ya comentado, de modo que los hijos, sin salirse del rol de hijo sometido a la voluntad materna, pueden manifestar iniciativa y formular preguntas directas sin poner en peligro sus imágenes, por lo que no se ven en la necesidad de realizar ningún tipo de actividad de imagen. Esto, a su vez, puede significar el comienzo de las manifestaciones del componente sociocultural español de la confianza $(\S 3)$ en la relación entre madres e hijos. 
Debe mencionarse que se ha registrado la emisión de una orden por parte de Clara a su madre y a su hermano, pero no nos detendremos en su análisis, ya que es fruto de un momento de tensión y no se presenta como una pauta propia del comportamiento comunicativo de la joven.

Por lo tanto, puede observarse que la imagen social de los roles de madre e hijos proyectada en esta obra, perteneciente a la segunda mitad del siglo XIX, experimenta un discreto movimiento desde la jerarquía absoluta presente en El sí de las niñas (1806) hacia una relación en la que la distancia social va disminuyendo al entrar en consideración las necesidades de autonomía de los hijos, así como la preocupación por expresar la afiliación de las madres con los hijos. Esto, unido a la ausencia de atenuación en las preguntas de información, puede explicarse por la paulatina presencia del contenido sociocultural español de confianza, una de cuyas vertientes la compone la afirmación de la proximidad social (Hernández Flores 2003: 127).

\subsubsection{Historia de una escalera (Buero Vallejo 1949)}

En 1949 estrena Buero Vallejo Historia de una escalera, obra con la que el "realismo tradicional y acuciante reaparece en la escena española" (Blanco Aguinaga et alii 2000: 526) después de la Guerra Civil. Esta obra resulta de gran interés para nuestro análisis pues representa la vida cotidiana de varias familias a lo largo de tres generaciones en un vecindario en un arco temporal que abarca desde 1919 hasta 1949. Los resultados obtenidos los recogemos en las siguientes tablas (vid. Tablas 5 y 6 ):

\begin{tabular}{|c|c|c|c|}
\hline Directivos a favor del hablante & & Directivos a favor de oyente & \\
\hline $\begin{array}{r}\text { Preguntas de información (11) } \\
\text { atenuadas (0) } \\
\text { no atenuadas (11) }\end{array}$ & $\begin{array}{l}55 \% \\
0 \% \\
100 \%\end{array}$ & $\begin{array}{r}\text { Consejos o sugerencias }(0) \\
\text { atenuadas }(0) \\
\text { no atenuadas }(0)\end{array}$ & $\begin{array}{ll}0 & \% \\
0 & \% \\
0 & \%\end{array}$ \\
\hline $\begin{array}{r}\text { atenuadas }(0) \\
\text { no atenuadas }(0)\end{array}$ & $\begin{array}{ll}0 & \% \\
0 & \% \\
0 & \%\end{array}$ & \begin{tabular}{|r|}
$\begin{array}{l}\text { Advertencias en beneficio del } \\
\text { oyente }(0) \\
\text { atenuadas }(0) \\
\text { no atenuadas }(0)\end{array}$ \\
\end{tabular} & $\begin{array}{ll}0 & \% \\
0 & \% \\
0 & \%\end{array}$ \\
\hline $\begin{array}{r}\text { Atenuadas (5) } \\
\text { no atenuadas (4) }\end{array}$ & $\begin{array}{l}45 \% \\
55,5 \% \\
44,5 \%\end{array}$ & & \\
\hline $\begin{array}{l}\text { Total directivos a favor del hablante: } \\
20 \\
\text { Atenuados: } 5(25 \%) \\
\text { No atenuados: } 15(75 \%)\end{array}$ & & $\begin{array}{l}\text { Directivos a favor del oyente: } 0 \\
\text { Atenuados: } 0(0 \%) \\
\text { No atenuados: } 0(0 \%)\end{array}$ & $0 \%$ \\
\hline $\begin{array}{l}\text { TOTAL } \\
\text { Actos de habla directivos atenuados: } \\
25 \%(5) \\
\text { Actos de habla directivos no } \\
\text { atenuados: } 75 \%(14)\end{array}$ & & & \\
\hline
\end{tabular}

Tabla 5. Datos de los actos directivos realizados por los personajes en rol de madre en Historia de una escalera (1949). 


\begin{tabular}{|c|c|c|c|}
\hline Directivos a favor del hablante & & Directivos a favor de oyente & \\
\hline $\begin{array}{r}\text { Preguntas de información (4) } \\
\text { atenuadas (1) } \\
\text { no atenuadas (3) }\end{array}$ & $\begin{array}{l}44,5 \% \\
25 \% \\
75 \%\end{array}$ & $\begin{array}{r}\text { Consejos o sugerencias }(0) \\
\text { atenuadas }(0) \\
\text { no atenuadas }(0)\end{array}$ & $\begin{array}{ll}0 \% \\
0 \% \\
0 \%\end{array}$ \\
\hline $\begin{array}{r}\text { atenuadas }(2) \\
\text { no atenuadas }(0)\end{array}$ & $\begin{array}{l}22,2 \% \\
100 \% \\
0 \%\end{array}$ & $\begin{array}{l}\text { Advertencias en beneficio del oyente } \\
(0) \\
\text { atenuadas }(0) \\
\text { no atenuadas }(0)\end{array}$ & $\begin{array}{ll}0 \% \\
0 \% \\
0 \%\end{array}$ \\
\hline $\begin{array}{r}\text { atenuadas (1) } \\
\text { no atenuadas (2) }\end{array}$ & $\begin{array}{l}33,3 \% \\
33,4 \% \\
66,6 \% \\
\end{array}$ & & \\
\hline $\begin{array}{l}\text { Total directivos a favor del hablante: } 9 \\
\text { Atenuados: } 4(44,5 \%) \\
\text { No atenuados: } 5(55,5 \%)\end{array}$ & & $\begin{array}{l}\text { Directivos a favor del oyente }(0) \\
\text { Atenuados: } 0 \% \\
\text { No atenuados: } 0 \%\end{array}$ & $0 \%$ \\
\hline
\end{tabular}

Tabla 6. Datos de los actos directivos realizados por los personajes en rol de hijos en Historia de una escalera (1949).

Tal y como reflejan los datos en la tabla correspondiente a las madres (vid. Tabla 5), solo se observan dos tipos de actos directivos: las preguntas de información y las órdenes. No se registran así ni solicitudes ni ningún directivo en favor del oyente. Llama la atención el aumento del número de preguntas de información realizadas, y el hecho de que ninguna de ellas sea atenuada. Esto puede tener relación con el progresivo desplazamiento hacia el eje de solidaridad al que hemos hecho referencia, apoyado por el afianzamiento de la ya mencionada confianza entre madres e hijos, de manera que cada vez las relaciones se basan más en este componente y menos en la jerarquía o el poder. De esta manera, las madres poseen la confianza de poder preguntar abiertamente a sus hijos sin que estos sientan amenazada su imagen, por lo que no hay necesidad de recurrir a ningún tipo de estrategia pragmática ni actividad de imagen para salvaguardar la imagen ni de hablantes ni de receptores.

En cuanto a las órdenes, estas son atenuadas en el 55,5\% de los casos (exactamente en el mismo porcentaje que en la obra de la segunda mitad del siglo XIX), lo que parece apuntar a que siguen siendo consideradas amenazas potenciales a la imagen de los interlocutores. En esta obra, la técnica lingüística más utilizada es la justificación, que funciona a lo largo de toda la obra, tal y como se muestra en los siguientes ejemplos:

(17) Paca: ¡Que lo compres tinto! Que ya sabes que a tu padre no le gusta el blanco. (p. 60)

(18) Paca: Trae el capacho. Yo iré. Ve con tu padre, que tú sabes consolarle (p. 92)

Se observa que, en ambas intervenciones, Paca, en su rol de madre, realiza un acto directivo en su propio beneficio y lo atenúa a través de una justificación introducida por 
la conjunción que, cuya función es la reparación del daño producido a las necesidades de autonomía de su hija Trini. Se ha producido, por tanto, una actividad de cortesía que ha tratado de recuperar el equilibrio entre las imágenes de ambas, pues la madre ha dañado la de su hija con un mandato tan directo. Puede desprenderse de esto (patrón repetido en más ocasiones a lo largo de la obra) que las madres representadas en esta obra, reflejo del periodo postfranquista, sienten mayor necesidad de justificar los actos directivos a sus hijos que en las obras analizadas del siglo XIX, ya que han ido adquiriendo paulatinamente una mayor importancia las necesidades de autonomía de estos.

Sin embargo, en la siguiente ocasión, Paca nuevamente realiza un acto directivo en su propio beneficio dirigido a su hija y que no se atenúa; esto se debe a que es la reiteración de un mandato previamente realizado y que la hija no ha cumplido. En contraposición con lo que se esperaría de una situación así en el siglo XIX, no hay una disculpa por parte de Trini, lo que confirma la presencia del elemento de la confianza entre madres e hijas: Trini actúa libremente de acuerdo con su propia personalidad sin miedo a ofender a su madre, sabiendo que esta conducta será recibida con naturalidad (Hernández Flores 2003: 122):

(19) Paca: ¡Claro que tengo razón! ( $A$ Trini.) ¿Qué haces aquí todavía? ¡Anda a la compra! Trini: (Desde dentro.) Se me pasó. A eso subía. (p. 92)

En cuanto al empleo de la atenuación en los actos directivos realizados por los personajes en el rol de hijos, como se desprende del cuadro (vid. Tabla 6), al igual que sucede con las madres en el caso de las preguntas de información, en la mayoría de los casos $(75 \%)$ no aparecen atenuadas, lo que parece confirmar la presencia de la confianza.

En cuanto a las solicitudes, cuya realización entraña un mayor riesgo para la imagen de los interlocutores (en este caso para las necesidades de autonomía de la madre y las de afiliación de los hijos), son atenuadas en las dos ocasiones en las que se realizan (de ahí inferimos que las necesidades de autonomía de la madre son muy valoradas). En ambas se utiliza como táctica lingüística el apelativo madre, que refuerza las necesidades de afiliación entre madre e hija y minora la fuerza ilocutiva de su petición:

(20) Carmina: No se apure, madre (p. 83)

(21) Carmina: Ande, madre...Ande... (p. 81)

Por último, cabe destacar que, por primera vez, se aprecia la presencia de la emisión de órdenes por parte de los hijos a sus madres. Se han contabilizado un total de 3 órdenes, dos de las cuales (22) y (23) no son atenuadas y producen una actividad de imagen de descortesía, ya que resultan dañadas las imágenes de ambos interlocutores sin ser reparadas:

(22) Fernando: (Volviéndose hacia su madre.) ¡Sí! ¡Ya me lo has dicho! (Yendo hacia ella.) ¡Déjame en paz! (p. 61)

(23) Fernando: (Empujándola y cerrando de golpe.) ¡Anda, anda para adentro! (p. 62)

Puede, por tanto, observarse en la ausencia y presencia de la atenuación en la emisión de actos directivos cómo la relación entre madre e hijos en Historia de una escalera es 
sensiblemente menos desigual que las desarrolladas en las dos obras analizadas de etapas anteriores, pues se basa más en un carácter horizontal de confianza y progresiva solidaridad que en la autoridad de la madre. Las necesidades de autonomía de la madre son muy valoradas pero también las madres muestran respeto hacia las de sus hijos. Asimismo, el componente de la confianza se afianza, ya que se neutralizan con mayor frecuencia las posibles amenazas a la imagen, lo que se traduce en la mayor ausencia de actividades de imagen en los actos directivos de menos intensidad ilocutiva como las preguntas de información.

\subsubsection{Fuiste a ver a la abuela??? (Cabal 1979)}

Por último, presentamos el análisis de los diálogos madre-hijo en la obra de Fermín Cabal Fuiste a ver a la abuela??? (1979), obra de temática realista postfranquista situada entre el desarrollo del teatro independiente de finales de siglo y la comedia naturalista con motivos contemporáneos (Prieto de Paula y Langa Pizarro [2007: 269]). En ella, a través de los parlamentos de los personajes, carentes de algunos de nombre propio denominados tan solo por su rol familiar (Madre, Padre, Abuela), lo que es señal del deseo del autor de representar a la sociedad y de reflejar las relaciones familiares, se simboliza la mesocracia familiar propia de los años setenta y ochenta en España. Analizamos a continuación los actos directivos de los personajes Madre y Miguel y Antonio (los hijos) así como entre Padre y Abuela (entre los que hay, asimismo, relación materno-filial):

\begin{tabular}{|c|c|c|c|}
\hline Directivos a favor del hablante & & Directivos a favor de oyente & \\
\hline $\begin{array}{r}\text { Preguntas de información (7) } \\
\text { Atenuadas (2) } \\
\text { no atenuadas (5) }\end{array}$ & $\begin{array}{l}26,92 \% \\
28,57 \% \\
71,42 \%\end{array}$ & $\begin{array}{r}\text { Consejos o sugerencias (2) } \\
\text { Atenuadas (1) } \\
\text { no atenuadas( } 1)\end{array}$ & $\begin{array}{l}50 \% \\
50 \%\end{array}$ \\
\hline $\begin{array}{r}\text { atenuadas }(0) \\
\text { no atenuadas (1) }\end{array}$ & $\begin{array}{l}3,8 \% \\
0 \% \\
100 \%\end{array}$ & $\begin{array}{l}\text { Advertencias en beneficio del } \\
\text { oyente (0) } \\
\qquad \begin{array}{r}\text { atenuadas }(0) \\
\text { no atenuadas }(0)\end{array}\end{array}$ & $\begin{array}{l}0 \% \\
0 \% \\
0 \%\end{array}$ \\
\hline $\begin{array}{r}\text { Atenuadas (5) } \\
\text { no atenuadas (13) }\end{array}$ & $\begin{array}{l}69,23 \% \\
27,77 \% \\
72,22 \%\end{array}$ & & \\
\hline $\begin{array}{r}\text { Total directivos a favor del hablante: } 26 \\
\text { Atenuados: } 7 \\
\text { No atenuados: } 19\end{array}$ & $\begin{array}{l}26,92 \% \\
73,07 \%\end{array}$ & $\begin{array}{r}\text { Directivos a favor del oyente: } 2 \\
\text { Atenuados: } 1 \\
\text { No atenuados: } 1\end{array}$ & $\begin{array}{l}50 \% \\
50 \%\end{array}$ \\
\hline \multicolumn{4}{|c|}{$\begin{array}{l}\text { TOTAL } 28 \\
\text { Actos de habla directivos atenuados: } 28,57 \%(8) \\
\text { Actos de habla directivos no atenuados: } 71,42 \%(20)\end{array}$} \\
\hline
\end{tabular}

Tabla 7. Datos de los actos directivos realizados por el personaje en rol de madre en Fuiste a ver a la abuela??? (1979). 


\begin{tabular}{|c|c|c|c|}
\hline Directivos a favor del hablante & & Directivos a favor de oyente & \\
\hline $\begin{array}{r}\text { Preguntas de información (4) } \\
\text { Atenuadas (1) } \\
\text { no atenuadas (3) }\end{array}$ & $\begin{array}{l}80 \% \\
25 \% \\
75 \%\end{array}$ & $\begin{array}{r}\text { Consejos o sugerencias }(0) \\
\text { atenuadas }(0) \\
\text { no atenuadas }(0)\end{array}$ & $\begin{array}{l}0 \% \\
0 \% \\
0 \%\end{array}$ \\
\hline $\begin{array}{r}\text { atenuadas (1) } \\
\text { no atenuadas (0) }\end{array}$ & $\begin{array}{l}20 \% \\
100 \\
\% \\
0 \%\end{array}$ & $\begin{array}{l}\text { Advertencias en beneficio del } \\
\text { oyente }(0) \\
\text { atenuadas }(0) \\
\text { no atenuadas }(0)\end{array}$ & $\begin{array}{l}0 \% \\
0 \% \\
0 \%\end{array}$ \\
\hline $\begin{array}{r}\text { atenuadas }(0) \\
\text { no atenuadas }(0)\end{array}$ & $\begin{array}{l}0 \% \\
0 \% \\
0 \% \\
\end{array}$ & & \\
\hline $\begin{array}{r}\text { Total directivos a favor del hablante: } 5 \\
\text { atenuados: } 2 \\
\text { no atenuados: } 3\end{array}$ & $\begin{array}{l}40 \% \\
60 \% \\
\end{array}$ & $\begin{array}{r}\text { Directivos a favor del oyente: }(0) \\
\text { atenuados: }(0) \\
\text { no atenuados: }(0)\end{array}$ & $\begin{array}{l}0 \% \\
0 \% \\
0 \% \\
\end{array}$ \\
\hline \multicolumn{4}{|l|}{$\begin{array}{l}\text { TOTAL actos de habla directivos: } 5 \\
\text { Actos de habla directivos atenuados: } 40 \% \text { (2) } \\
\text { Actos de habla directivos no atenuados: } 60 \% \text { (3) }\end{array}$} \\
\hline
\end{tabular}

Tabla 8. Datos de los actos directivos realizados por el personaje en rol de hijo en Fuiste a ver a la abuela??? (1979).

En primer lugar, puede observarse que, en lo que respecta al porcentaje total de directivos atenuados por la madre $(28,57 \%)$ y por los hijos $(40 \%)$, es similar al observado en Historia de una escalera (25\% y $44 \%$ respectivamente); sin embargo, la distribución de estos ha variado.

En cuanto a la enunciación de preguntas, tanto en las realizadas por la madre como por los hijos (vid. Tablas 7 y 8), sigue habiendo una gran mayoría de no atenuados, lo que confirma la consolidación de la confianza entre madres e hijos, a excepción de casos como (24) y (25), atenuadas a través de apelativos familiares que refuerzan las necesidades de afiliación:

(24) Miguel: ¿Para qué, mamá? (p. 95)

(25) Madre: Pero hijo... ¿y el calcetín? (p. 93)

En cuanto a la emisión de órdenes por parte de la madre (vid. Tabla 7), 13 de las 18 no son atenuadas. Destaca que en dos de las ocasiones la madre atenúa su implicación en el mandato, cuyo cumplimiento ella también desea, aludiendo a la responsabilidad del padre (con lo que realiza una actividad de autoimagen), de lo que interpretamos que la figura paterna ostenta aún más poder y autoridad en la relación con sus hijos que la madre. Así, en dos ocasiones (26 y 27), además de atenuar su orden expresándola indirectamente a través de una frase afirmativa, la madre encubre su propia voz en la voluntad del padre.

(26) Madre: Harás lo que diga tu padre (p. 82)

(27) Madre: Tu padre ha dicho que de general (p. 82) 
No sucede lo mismo en (28), donde la atenuación se expresa a través del apelativo hijo y de la disculpa, no en la aparición de la figura paterna ya que se entiende que en esta ocasión el mandato es solo deseo del padre:

(28) Madre: Lo siento, hijo, tendrás que irte de casa hasta que se le pase a tu padre (p. 115)

Puede observarse, de los datos de esta obra, que la relación madre-hijos continúa con los patrones comunicativos de los actos directivos en una línea muy similar a la obra representativa de la primera mitad de siglo. Si bien no se han registrado órdenes por parte de los hijos a la madre, el reducido uso de atenuación en el resto de actos directivos en ambas direcciones nos lleva de nuevo a pensar en la confianza como base de la relación.

\section{CONCLUSIONES}

Después de los análisis y consideraciones presentadas en este artículo hemos llegado a las siguientes conclusiones en relación con las dos hipótesis de partida:

Por una parte, se ha podido observar que, efectivamente, en los diálogos reproducidos en las obras de teatro es posible analizar las actividades de imagen y las diferencias entre obras escritas en diferente periodo en cuanto a los contenidos socioculturales de imagen (concretamente, de los roles de hijos y madre). Asimismo, el análisis desarrollado refuerza la idea de que la noción de imagen forma parte de la definición de atenuación en tanto que la presencia o ausencia de esta estrategia ha reflejado su evolución.

Por otra parte, de los datos arrojados por el análisis de la atenuación, discernimos que en estas cuatro obras se refleja un cambio en las relaciones materno-filiales desde el siglo XIX hasta finales del siglo XX: del estudio de los textos presentados en este trabajo se desprende, a partir del estudio de la presencia y comportamiento de la atenuación, un desplazamiento de las relaciones materno-filiales desde una jerarquía basada en la autoridad de la madre hacia una progresiva solidaridad basada en la confianza entre madres e hijos. Nos sirve de dato ilustrativo la evolución de las estrategias de atenuación en las órdenes: en El sí de las niñas la madre atenuaba solo un $25 \%$ de los casos, porcentaje que se incrementó en La bola de nieve (finales del siglo XIX) y en Historia de una escalera (primera mitad del siglo XX) hasta un 55,5\%. Este ascenso en la atenuación de las órdenes puede estar relacionado con un incremento progresivo de la consideración paulatina de las necesidades de autonomía en la imagen de los hijos, que cada vez van adquiriendo mayor libertad de actuación. Sin embargo, en la obra de finales del siglo XX el índice de atenuación en las órdenes bajaba nuevamente al $27 \%$, lo que se explica no por la autoridad maternal sino por el afianzamiento progresivo de la confianza entre madres e hijos, que implicaría una menor preocupación por las posibles ofensas entre los interlocutores.

Este aumento de la confianza es muy evidente también en los directivos realizados por los hijos, especialmente en el caso de las preguntas de información. Así, mientras en el teatro de comienzos del siglo XIX eran atenuadas en la totalidad de los casos, es posible apreciar un progresivo descenso en el uso de la atenuación en su formulación (hasta el $25 \%$ ) en las obras del siglo XX. Esto puede ser síntoma de cómo los hijos han adquirido confianza con sus progenitoras y no se ven en la necesidad de realizar actividades de imagen ante la realización de preguntas. 
En cuanto a las tácticas lingüísticas que canalizan la atenuación, concluimos de este análisis que no hay diferencias con las técnicas de atenuación del español contemporáneo ya que todas las tácticas registradas se encuentran en el repertorio confeccionado por Albelda et alii (2014) para el análisis de la atenuación en el español hablado actual.

No obstante, conviene remarcar que estas conclusiones se basan en el análisis de cuatro obras concretas. Para poder afirmar con rotundidad estas conclusiones sería necesario analizar un abanico más amplio de obras, pues, de acuerdo con Bravo (2002: 105), "para que hablemos de un contenido de la imagen del rol que sea extensivo a un grupo de personas, estos conceptos tienen que tener un carácter más o menos estable; es decir, poder ser evaluados como contenidos de identidad". Además, sería necesario, como se pretende en fases posteriores de esta investigación, contrastar los resultados del análisis pragmático con estudios histórico-sociales. Igualmente, se hace deseable para futuras investigaciones incorporar variables sociolingüísticas que proporcionen datos más completos que nos permitan definir periodos socioculturales concretos con contenidos de imagen específicos asociados a los diferentes roles.

\section{Referencias bibliográficas}

Albelda, M. (2004). "Cortesía en diferentes situaciones comunicativas. La conversación coloquial y la entrevista sociológica semiformal". En Bravo, D. y A. Briz (eds.). Pragmática sociocultural. Estudios sobre el discurso de cortesía en español. Barcelona: Ariel Lingüística pp. 109-134.

Albelda, M. (2008). "Influence of situational factors on the codification and interpretation of impoliteness", Pragmatics 18(4), pp. 751-773.

Albelda, M. (2010). “¿Cómo se reconoce la atenuación? Una aproximación metodológica basada en el español peninsular hablado”. En Orletti, F. y L. Mariottini (eds). (Des) cortesía en español. Espacios teóricos y metodológicos para su estudio. Estocolmo-Roma: Università degli Studi Roma Tre- EDICE, pp. 41-70.

Albelda, M. (2016). "Sobre la incidencia de la imagen en la atenuación pragmática". En Mihatsch, W. y M. Albelda (eds.), Revista Internacional de Lingüística (RILI), 27, pp. 19-31.

Albelda, M. y J. Contreras (2009). "Imagen de afiliación y atenuantes en un análisis contrastivo alemán/español”. En Bernal, M. y N. Hernández-Flores (eds.). Estudios sobre lengua, discurso y sociedad: Homenaje a Diana Bravo. Estocolmo: Universidad de Estocolmo, pp. 7-30.

Albelda, M., Briz, A., Cestero, A.M., Kotwica, D. y C. Villalba (2014). "Ficha metodológica para el análisis pragmático de la atenuación en corpus discursivos del español. ES.POR.ATENUACIÓN”, Oralia, 17, pp. 1-44.

Arundale, R. (2006). "Face as relational and interactional: a communication framework for research on face, facework, and politeness". Journal of Politeness Research, 2(2), pp. 193-216.

Arundale, R. (2013). “Is face the best metaphor? / ¿Es imagen social la mejor metáfora?”, Pragmática Sociocultural, 1 (2), pp. 282-295.

Bentivoglio, P. (2003). "Formas de tratamiento en cartas de la segunda mitad del siglo XVI: una aproximación pragmática", Archivo de filología aragonesa, Vol. 59-60, 1, pp. 229-248.

Blanco Aguinaga, C., Rodríguez Puértolas, J. e I. M. Zavala (2000). Historia social de la literatura española (en lengua castellana), Vol. II. Madrid: Ediciones Akal.

Bravo, D. (1998). "FACE y rol social: eficiencia comunicativa en encuentros entre hablantes nativos y no nativos del español", Revista de Estudios de Adquisición de la Lengua Española, 8, pp. 11-41.

Bravo, D. (1999). “¿Imagen 'positiva' vs. imagen 'negativa’? Pragmática socio-cultural y componentes de face", Oralia, 2, pp. 155-184. 
Bravo, D. (2002). "Actividades de cortesía, imagen social y contextos socioculturales: una introducción”. En Bravo, D. (ed.). Actas del Primer Coloquio EDICE. La perspectiva no etnocentrista de la cortesía: Identidad sociocultural de las comunidades hispanohablantes. Stockholm: University of Stockholm. pp. 96-108.

Bravo, D. (2004): "Tensión entre universalidad y relatividad en las teorías de la cortesía". En Bravo, D. y A. Briz (eds.). Pragmática sociocultural. Estudios sobre el discurso de cortesía en español. Barcelona: Ariel, pp. 15-37.

Bravo, D. (2010). "Pragmática sociocultural. La configuración de la imagen social como premisa socio-cultural para la interpretación de actividades verbales y no verbales de la imagen". En Orletti, F. y L. Mariottini (eds). (Des)cortesía en español. Espacios teóricos y metodológicos para su estudio. Estocolmo-Roma: Università degli Studi Roma Tre- EDICE, pp. 19-46.

Briz, A. (1998). "Estrategias de producción-recepción: la atenuación en la conversación coloquial”. En El español coloquial en la conversación. Esbozo de pragmagramática. Barcelona, Ariel, pp. 143-163.

Briz, A. (2003). "La estrategia atenuadora en la conversación cotidiana española". En Bravo, D. (ed.). La perspectiva no etnocentrista de la cortesía: identidad sociocultural de las comunidades hispanohablantes. Estocolmo: Universidad de Estocolmo, pp. 17-46.

Briz, A. (2005). "Eficacia, imagen social e imagen de cortesía". En Bravo, D. (ed.). Estudios de la (des)cortesía en español. Buenos Aires: Dunken, pp. 53-91.

Briz, A. (2006). "Para un análisis semántico, pragmático y sociopragmático de la cortesía atenaudora en España y América", Lingüística Española Actual, vol. XXIX/1, pp. 5-44.

Briz, A. (2012). "La (no) atenuación y la (des)cortesía, lo lingüístico y lo social: ¿son pareja?”. En Escamilla Morales, J. y H. Vega (eds.). Miradas multidisciplinares a los fenómenos de cortesía y descortesía en el mundo hispánico. Barranquilla: Universidad del Atlántico-Programa EDICE, pp. 33-75.

Brown R. y A. Gilman (1960). "The pronouns of power and solidarity". En T. Sebeok (ed.). Style in language. Cambridge-Mass: MIT Press, pp. 255-276.

Brown R. y A. Gilman (1989). "Politeness theory and Shakespeare's four major tragedies", Language and Society, 18 (2), pp. 159-212.

Brown, P. y S. Levinson (1987 [1978]). Politeness. Some universals in language usage. Cambridge: Cambridge University Press.

Caffi, C. (1999): “On mitigation", Journal of Pragmatics, 31, pp. 881-909.

Caffi, C. (2007): Mitigation. Oxford: Elsevier.

Carrera de la Red, M. (2012). “Apropiación e imitación, procesos en la formación del registro periodístico colombiano del siglo XIX”, Revista internacional de lingüística iberoamericana, 20, pp. 11-26.

Carrera de la Red, M. (2013). "Análisis del discurso y sociopragmática histórica en un debate legal en la Cartagena de Indias del siglo XVIII. Intensificación y atenuación como recursos argumentales", Pragmática Sociocultural, 1 (2), pp. 11-45.

Carrera de la Red, M. (2015). "Identidad, imagen y (des)cortesía en Cartagena de Indias (siglo XVII). Diálogos surgidos desde el enfrentamiento étnico". Textos en proceso, 1 (2), pp. 206-236.

Carrera de la Red, M. y A. Álvarez (2004). "Tratamientos y cortesía en la elaboración de fuentes documentales de la etapa fundacional de la provincia de Mérida (Venezuela)". En Bravo, D. y A. Briz (eds.). Pragmática sociocultural. Estudios sobre el discurso de cortesía en español. Barcelona: Ariel, pp. 227-243.

Cestero, A.M. (2015). "La atenuación lingüística en el habla de Madrid: un fenómeno sociopragmático variable". En Cestero, A.M., Molina, I. y F. Paredes (eds.). Patrones sociolingüísticos de Madrid. Bern: Peter Lang, pp. 365-412.

Culpeper, J. (1996). "Towards an anatomy of impoliteness", Journal of Pragmatics, 25 (3), pp. 349367.

Faya Cerqueiro, F. y Z. Vila Carneiro (2014). "Ampliando horizontes de investigación a través de la cooperación interdisciplinaria en Filología: el caso de la pragmática histórica", e-Scripta Romanica, 1, pp. 55-74. 
Faya Cerqueiro, F. y Z. Vila Carneiro (2016). "Consideraciones acerca de la fórmula de despedida $a$ Dios en el teatro del Siglo de Oro”, Onomázein, 33, pp. 39-56.

Fraser, B. (1980). “Conversational mitigation”, Journal of Pragmatics, 4, pp. 341-350.

Gancedo Ruiz, M. (2016). "El texto dramático literario como corpus para el análisis histórico de las actividades de imagen", Textos en Proceso 2(1), pp. 162-173.

García Aguiar, L.C. (2012). "El sistema de tratamientos en las Novelas Ejemplares de Cervantes”. En Mortero Cartelle, E. y C. Manzano Rovira. Actas del VIII Congreso Internacional de Historia de la Lengua Española. Santiago de Compostela, pp. 2107-2178.

Goffman, E. ([1959] 2009). La presentación de la persona en la vida cotidiana. Buenos Aires: Amorrortu.

Hamad Zahonero, N. (2012): "La expresión de la cortesía verbal en el s. XIII: la PCG y Berceo". En Mortero Cartelle, E. y C. Manzano Rovira. Actas del VIII Congreso Internacional de Historia de la Lengua Española. Santiago de Compostela, pp. 2219-2228.

Haverkate, H. (1991). "Una conversación entre Calisto, Sempronio y Pármeno", Foro Hispánico 2. Exploraciones semánticas y pragmáticas del español, pp. 109-119.

Haverkate, H. (2001). “Cortesía y descortesía en los diálogos del Quijote. Análisis de la representación de las imágenes positiva y negativa de los protagonistas”, Oralia, 4, pp. 129-148.

Hernández-Flores, N. (2002). La cortesía en la conversación española de familiares y amigos; la búsqueda del equilibrio entre la imagen del hablante y la imagen del destinatario. Aalborg: Aalborg Universitet.

Hernández-Flores, N. (2003). "Cortesía y contextos socioculturales en la conversación española de familiares y amigos". En Bravo, D. (ed.). Actas del Primer Coloquio del Programa EDICE. La perspectiva no etnocentrista de la cortesía: identidad sociocultural de las comunidades hispanohablantes. Estocolmo: Universidad de Estocolmo, pp. 121-127.

Hernández-Flores, N. (2006). "La cortesía como búsqueda del equilibrio de la imagen social: La oscilación de la imagen en un debate televisivo". En Murillo, J. (ed.). Actas del II Coloquio del Programa EDICE. San José/Estocolmo: Universidad de Costa Rica/Programa EDICE, pp. 37-52.

Hernández-Flores, N. (2013). “Actividad de imagen. Caracterización y tipología en la interacción comunicativa", Pragmática Sociocultural, 1(2), pp. 1-24.

Holmes, J. (1984). "Modifying illocutionary force”, Journal of Pragmatics, 8, pp. 345-365.

Iglesias Recuero, S. (2010). "Aportación a la historia de la (des)cortesía: las peticiones en el siglo XVI”. En Orletti, F. y L. Mariottini (eds.). (Des)cortesía en español. Espacios teóricos y metodológicos para su estudio. Roma/Estocolmo: Università degli Studi Roma Tre-EDICE/Universidad de Estocolmo, pp. 369-396.

Iglesias Recuero, S. (2016): "Otra cara de la Pragmática histórica: la historia de los actos de habla en español. Peticiones y órdenes en las Novelas ejemplares de Miguel de Cervantes". En López Serena, A., Narbona, A. y S. del Rey Quesada (coords.). El español a través del tiempo. Estudios ofrecidos a Rafael Cano Aguilar. Sevilla: Editorial Universidad de Sevilla.

Jacobs, A. y A.H. Jucker (1995). "The Historical Perspective in Pragmatics". En Jucker, A.H. Historical Pragmatics: Pragmatics Developments in the History of English. Amsterdam: John Benjamins, pp. 3-33.

Jucker, A. H. (1995). Historical Pragmatics: Pragmatics Developments in the History of English. Amsterdam: John Benjamins

Matsumoto, Y. (1988). "Reexamination of the university of face: Politeness phenomena in japanese", Journal of Pragmatics, 12, pp. 403-426.

Moreno, M. (2002). "La cortesía verbal en el Siglo de Oro. Los actos de habla defectivos: Un estudio de pragmática histórica”. En Echenique, M.T. y J. P. Sánchez Méndez (coords.). Actas del V Congreso Internacional de Historia de la Lengua Española. Madrid: Gredos, pp. 1347-1360.

Moreno, M. (2008). "Análisis diacrónico de la cortesía verbal del español clásico al contemporáneo". En Briz, A., Hidalgo, A., Albelda, M., Contreras, J. y N. Hernández Flores (eds.). Cortesía y conversación: de lo escrito a lo oral. Tercer coloquio Internacional del Programa EDICE. Valencia: Universitat de Valéncia, pp. 410-418. 
Navarro Gala, R. (2004). "Formas de cortesía en la Segunda Celestina". En Bravo, D. y A. Briz (eds.). Pragmática sociocultural. Estudios sobre el discurso de cortesía en español. Barcelona: Ariel, pp. 213-225.

Pedroviejo Esteruelas, J. M. (2004). "Formas de tratamiento en dos obras de teatro del siglo XX: Historia de una escalera y Bajarse al moro”. En Bravo, D. y A. Briz (eds.). Pragmática sociocultural. Estudios sobre el discurso de cortesía en español. Barcelona: Ariel, pp. 245-262.

Padilla Cruz, M. (1998a). "Las estrategias de cortesía lingüística en los parlamentos dirigidos a la audiencia de los Mystery Plays de Inglés Medio: un enfoque social y cognitivo". Universidad de Sevilla, Tesis de Licenciatura.

Padilla Cruz, M. (1998b). "Las estrategias de cortesía lingüística en los parlamentos dirigidos a la audiencia de los Mystery Plays". Interlingüística, 9, pp. 241-245.

Padilla Cruz, M. (2002). "Lo que la pragmática puede aportar al estudio histórico del lenguaje". Res Diachronicae Virtual, 1, pp. 471-482.

Prieto de Paula, A. y M. Langa Pizarro (2007). Manual de Literatura Española actual. Madrid: Castalia.

Sbisá, M. (2001). "Illocutionary force and degrees of strength in language use", Journal of Pragmatics, 33, pp. 1791-1814.

Schneider, S. (2013). “Atenuación léxica y sintáctica”, Oralia, 16, pp. 335-356.

Schrader-Knifki, M. (2003). "Contraste de la imagen sociocultural y su función en situaciones comunicativas interculturales". En Bravo, D. (ed.). Actas del Primer Coloquio del Programa EDICE. La perspectiva no etnocentrista de la cortesía: identidad sociocultural de las comunidades hispanohablantes. Estocolmo: Universidad de Estocolmo, pp. 143-148.

Schrott, A. (2000). "¿Quí los podrié contar? Interrogative acts in the Cantar de mio Cid: Some examples from Old Spanish on asking questions", Journal of Historical Pragmatics, 37(2), pp. 263-299.

Stein, D. (1985). "Perspectives on historical pragmatics", Folia Linguistica Historica, 6(1), pp. 347-355.

Taavitsainen, I. (2002). "Historical discourse analysis. Scientific language and changing thoughstyles”. En Fanego, T., Méndez-Naya, B. y E. Seoane (eds.). Sounds, Words, Textsand Change. Amsterdam/Nueva York: John Benjamins, pp. 201-226.

Taavitsainen, I. y S. M. Fitzmaurice (2007). "Historical pragmatics: What it is and how to do it". En Fitzmaurice, S.M. e I. Taavitsainen (eds.). Methods in Historical Pragmatics. Berlin/New York: Mouton de Gruyter, pp. 11-36.

Thaler, V. (2012). "Mitigation as modification of illocutionary force", Journal of Pragmatics, 44, pp. 907-919.

Watts, R.J. y M. Locher (2005). "Politeness theory and relational work", Journal of Politeness Research, 1 (1), pp. 9-34.

Wierzbicka, A. (1985). "Different cultures, different languages, different speech acts", Journal of Pragmatics, 9, pp. 145-178.

Wierzbicka, A. (1991). Cross-Cultural Pragmatics. The semantics of Human Interaction. BerlínNueva York: Mouton de Gruyter.

Zamora, F.J. (2014). "Actividades de imagen en textos narrativos", Pragmática Sociocultural/Sociocultural Pragmatics, 1 (2), pp. 75-198.

\section{Obras de teatro analizadas}

Buero Vallejo, A. ([1949]2000). Historia de una escalera. Madrid: Espasa.

Cabal, F. ([1982] 1999). Fuiste a ver a la abuela??? Madrid: Editorial Fundamentos.

Fernández de Moratín, L. ([1806] 2014). El sí de las niñas. Edición de Emilio Martínez Mata. Madrid: Cátedra.

Tamayo y Baus, M. ([1856] 1999). La bola de nieve. Alicante: Biblioteca Virtual Miguel de Cervantes: http://www.cervantesvirtual.com/obra/la-bola-de-nieve--0/ (19-12-2016). 